\title{
Maternal health-related quality of life after induction of labor or expectant monitoring in pregnancy complicated by intrauterine growth retardation beyond 36 weeks
}

\author{
Denise Bijlenga · Kim E. Boers • Erwin Birnie • Ben-Willem J. Mol • \\ Sylvia C. M. Vijgen · Joris A. M. Van der Post • Christianne J. De Groot • \\ Robbert J. P. Rijnders • Paula J. Pernet • Frans J. Roumen • Rob H. Stigter • \\ Friso M. C. Delemarre - Henk A. Bremer • Martina Porath - Sicco A. Scherjon • \\ Gouke J. Bonsel
}

Accepted: 10 March 2011/Published online: 6 April 2011

(C) The Author(s) 2011. This article is published with open access at Springerlink.com

\begin{abstract}
Objective Pregnancies complicated by intrauterine growth retardation (IUGR) beyond 36 weeks of gestation are at increased risk of neonatal morbidity and mortality. Optimal treatment in IUGR at term is highly debated. Results from the multicenter DIGITAT (Disproportionate Intrauterine Growth Intervention Trial At Term) trial show that induction of labor and expectant monitoring result in equal neonatal and maternal outcomes for comparable cesarean section rates. We report the maternal healthrelated quality of life (HR-QoL) that was measured alongside the trial at several points in time.

Methods Both randomized and non-randomized women were asked to participate in the HR-QoL study. Women were asked to fill out written validated questionnaires,
\end{abstract}

This study is conducted for the DIGITAT study group. Other members of the DIGITAT study group are listed in the Appendix.

D. Bijlenga $(\bowtie)$ · B.-W. J. Mol · S. C. M. Vijgen ·

J. A. M. Van der Post

Department of Social Medicine, Academic Medical Center,

PO Box 22660, 1100 DD Amsterdam, The Netherlands

e-mail: denise.bijlenga@gmail.com

K. E. Boers - S. A. Scherjon

Leiden University Medical Center, Leiden, The Netherlands

E. Birnie - G. J. Bonsel

Erasmus Medical Center, Rotterdam, The Netherlands

C. J. De Groot

Medical Center Haaglanden, The Hague, The Netherlands

R. J. P. Rijnders

Jeroen Bosch Hospital, Den Bosch, The Netherlands

P. J. Pernet

Kennemer Gasthuis, Haarlem, The Netherlands covering background characteristics, condition-specific issues and the Short Form (SF-36), European Quality of Life (EuroQoL 6D3L), Hospital Anxiety and Depression scale (HADS), and Symptom Check List (SCL-90) at baseline, 6 weeks postpartum and 6 months postpartum. We compared the difference scores of all summary measures between the two management strategies by ANOVA. A repeated measures multivariate mixed model was defined to assess the effect of the management strategies on the physical (PCS) and mental (MCS) components of the SF-36. Analysis was by intention to treat.

Results We analyzed data of 361 randomized and 198 non-randomized patients. There were no clinically relevant differences between the treatments at 6 weeks or 6 months postpartum on any summary measures; e.g., on the SF-36 (PCS: $P=.09$; MCS: $P=.48$ ). The PCS and the MCS were below norm values at inclusion. The PCS improved

\author{
F. J. Roumen \\ Atrium Medical Center, Heerlen, The Netherlands \\ R. H. Stigter \\ Deventer Hospital, Deventer, The Netherlands \\ F. M. C. Delemarre \\ Elkerliek Hospital, Helmond, The Netherlands \\ H. A. Bremer \\ Reinier de Graaf Hospital, Delft, The Netherlands \\ M. Porath \\ Maxima Medical Center, Veldhoven, The Netherlands
}


over time but stayed below norm values at 6 months, while the MCS did not improve.

Conclusion In pregnancies complicated by IUGR beyond 36 weeks, induction of labor does not affect the long-term maternal quality of life.

Keywords Intrauterine growth retardation - Small for gestational age - Quality of life - Induction of labor . Expectant management

\section{Introduction}

Pregnancies complicated by intrauterine growth retardation (IUGR) are at increased risk for adverse neonatal outcome. Suspected IUGR often results in small-for-gestational age (SGA) neonates, perinatal mortality and morbidity, and adverse long-term health of the child [15]. IUGR is associated with hypertensive complications in pregnancy. Delivery to release the fetus from its nutritionally inadequate environment is thought to be the only feasible treatment $[6,7]$. However, there is no consensus regarding the optimal management strategy in IUGR at term. Induction of labor is believed to result in a higher chance of complications during delivery, while expectant monitoring provides a maximal chance of spontaneous labor at the expense of possible complications for the child.

We recently compared induction of labor and expectant monitoring in women with an IUGR-fetus beyond 36 weeks of gestation in a nationwide randomized clinical equivalence trial called DIGITAT (Disproportionate Intrauterine Growth Intervention Trial At Term; ISRCTN10363217). Results indicated that both treatments result in equal neonatal and maternal outcomes [8, 9]. Alongside the DIGITAT trial, we conducted a healthrelated quality of life (HR-QoL) study to examine the impact of the non-invasive (expectant monitoring) and the assumed invasive (induction of labor) strategy on the mother's self-reported health as a secondary outcome. Given the observed clinical equivalence, maternal outcomes gain importance to support clinical decisionmaking. HR-QoL can be an important factor for women to choose one treatment over the other and may lead to better treatment satisfaction.

We compared the impact of the two strategies at 6 weeks and at six moths postpartum in terms of self-reported health, anxiety, depression, and physical and mental symptoms, using validated questionnaires. The DIGITAT HR-QoL study includes observational data on patient outcome from patients refusing to participate in the trial to address potential bias from trial participation. We hypothesized that the invasive strategy would be more burdensome, as it was expected to be associated with a higher intervention rate such as instrumental delivery and cesarean sections.

\section{Methods}

Patients and clinical study

In the equivalence DIGITAT trial, primary outcome was defined as a composite neonatal adverse outcome, defined as death before hospital discharge, 5-min Apgar score $<7$, umbilical artery $\mathrm{pH}<7.05$, or admission to the neonatal intensive care. Eligible patients were women with a singleton pregnancy and a fetus in cephalic presentation between $36+0$ and $41+0$ weeks gestational age, with suspected IUGR. IUGR was defined as fetal abdominal circumference below the 10th percentile, estimated fetal weight below the 10th percentile and/or a decreased relative growth. Exclusion criteria were maternal age below 18 years, previous cesarean section, ruptured membranes, diabetes mellitus, renal disease, seropositivity for HIV, and HELLP syndrome (Hemolysis Elevated Liver enzymes, Low Platelet count) upon presentation. Women who refused randomization were included in the study as nonrandomized patients. Details of the study design have been described elsewhere [8,9].

All eight academic and 44 non-academic Dutch hospitals participated in the DIGITAT trial. The trial was approved by the Institutional Review Board of the University of Leiden (P170-99) and had local approval from the boards of the other participating hospitals. Women who were eligible for inclusion in the DIGITAT study received study information from a research nurse, midwife, resident, or gynecological staff member. Written informed consent was obtained from all patients prior to participation. Patients were randomly assigned to either induction of labor or expectant management. For logistic reasons, the inclusion for the HR-QoL study started in July 2005, 8 months after the start of the clinical trial; the last HR-QoL patient was included in October 2008. Individual and aggregate HRQoL results were not made available at any stage during the study. Figure 1 shows a flowchart of the study.

\section{Clinical interventions and procedure}

In women allocated to induction, labor was initiated within $48 \mathrm{~h}$ after randomization. Patients with a Bishop score $>6$ were induced for labor by amniotomy and, if needed, augmented with oxytocin. Patients with a lower Bishop score were primed with prostaglandins. In women allocated to the expectant group, fetal condition was monitored frequently during hospital or home-care admittance or in an outpatient setting, i.e., fetal movements as reported by the 


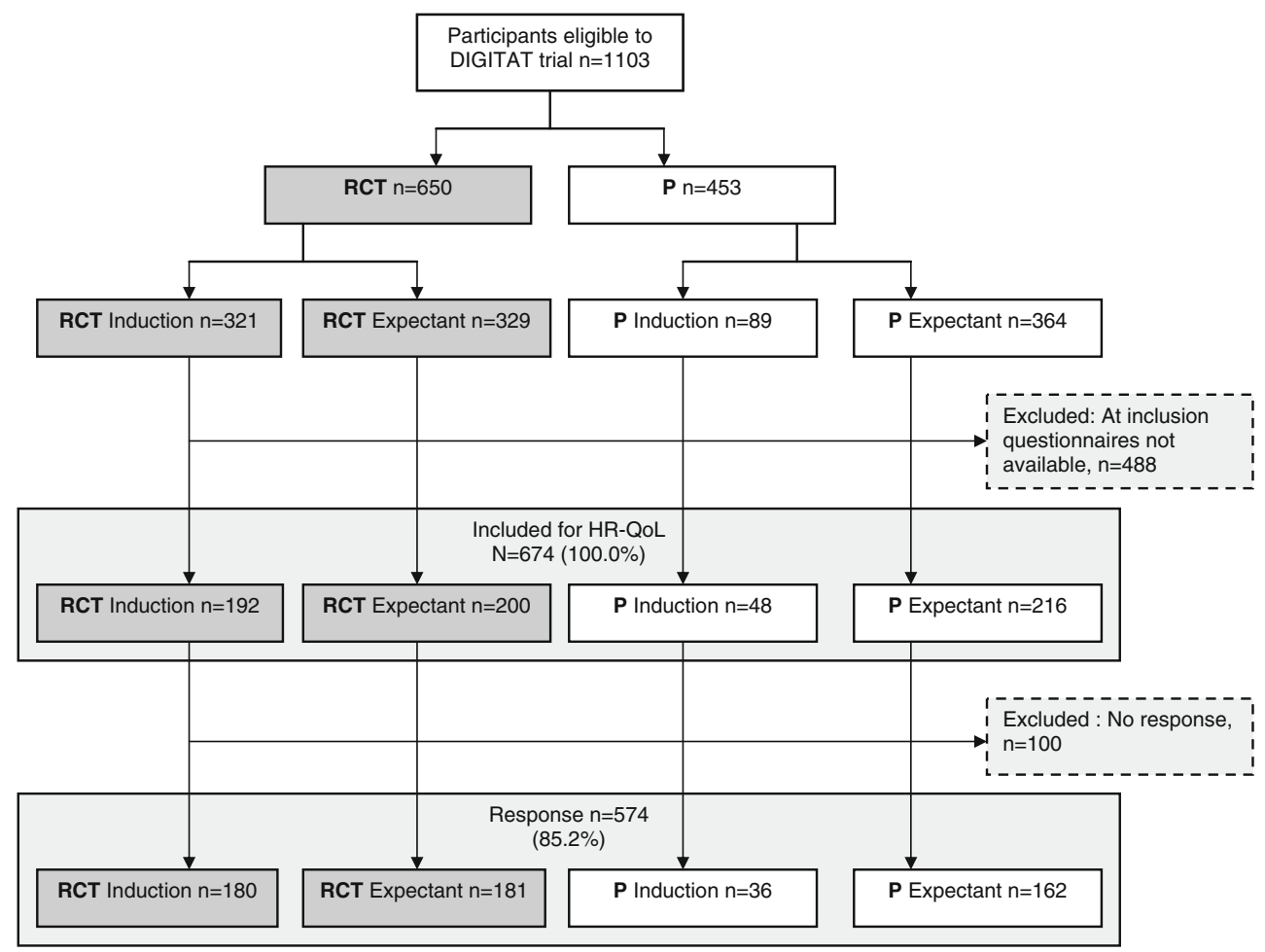

Fig. 1 Flowchart. $H R$ - $Q o L$ health-related quality of life, $R T C$ randomized controlled trial, $P$ treatment following protocol

mother, electronic fetal heart rate monitoring, and biophysical profile by ultrasound if indicated. Induction of labor was recommended in case of fetal distress, i.e., nonreassuring fetal heart rate or decreased or absent fetal movements. Among others, reasons for induction were prolonged rupture of membranes, pre-eclampsia, and postterm pregnancy. The study protocol has been described in more detail elsewhere [8, 9].

Background characteristics and clinical data (obstetric history, medical treatment, maternal and neonatal outcome, and interventions during hospital stay) were collected by local research midwives or nurses using a Web-based case record form. Data on maternal and neonatal mortality and morbidity as well as diagnoses at discharge were collected until 6 weeks postpartum. Outcomes of the DIGITAT trial indicated that the medical outcomes were equivalent between induction of labor and expectant management for composite adverse neonatal outcomes (resp. 6.1\% vs. $6.9 \% ; 95 \% \mathrm{CI}-4.9 \% ; 3.2 \%)$ and cesarean section rate (resp. $14.0 \%$ vs. $13.7 \%$; 95\% CI $-5.0 \% ; 5.6 \%$ ) [9].

\section{HR-QoL measures}

The participating women received a folder containing instructions, four HR-QoL questionnaires to be completed at baseline before inclusion/randomization (B1), at baseline after inclusion/randomization (B2), 6 weeks postpartum
(6W), and 6 months postpartum (6M). Each questionnaire took between 10 and $30 \mathrm{~min}$ to complete. The women also received four pre-stamped return envelopes, and reminder stickers-they women could stick these stickers in their agenda or on their calendar as a self-reminder for filling out a questionnaire on the appropriate date. The folders, including the questionnaires, were available in the Dutch and English languages. Patients who did not return questionnaire 6W within 7 weeks after delivery or questionnaire $6 \mathrm{M}$ within 7 months after delivery received a written reminder and a new copy of the questionnaire with a pre-stamped return envelope.

Questionnaire B1 contained questions on background characteristics, e.g., date of birth, educational level, employment characteristics, household composition, obstetric history, ethnicity, length, and weight before pregnancy. Questionnaire $6 \mathrm{~W}$ contained the retrospective report of pain after delivery at days 1, 4, and 7 after delivery, using a 4-point pain intensity scale and an 'I don't know' option. All questionnaires involved validated measures that will be elucidated later. We have used the Medical Outcome Study 36-Item Short Form Health Survey (SF-36; applied to questionnaires B1, $6 \mathrm{~W}, 6 \mathrm{M}$ ), the European Quality of Life 6 dimensions 3 levels (EuroQoL 6D3L) with subsequent general health Visual Analogue Scale (VAS; questionnaires B2, 6W, 6M), the Hospital Anxiety and Depression Scale (HADS; questionnaires B2, 6W, 6M), and the Symptom Check List (SCL-90; questionnaire 6M); all measures have been validated in Dutch and English [10-16]. 
The SF-36 is a generic questionnaire with eight healthstatus subscales: physical functioning, role limitations due to physical health problems, bodily pain, general health perception, vitality, social functioning, role limitations due to emotional health, and general mental health. The scores on the subscales are aggregated into the standardized summary scores Physical (PCS) and Mental Component Score (MCS). A standardized score of mean $=50$ and $\mathrm{SD}=10$ represents the Dutch population average [10, 11]. The EuroQoL 6D3L is an instrument to describe general health status with six dimensions (mobility, self-care, usual activities, pain/discomfort, anxiety/depression, and cognitive functioning). An individual's (or population's) health description can be expressed in a value between 0 (death) and 1 (perfect health) $[12,17]$. The subsequent VAS in our study is a vertical scale ('thermometer') with values 0 'worst possible health state' (lower anchor) to 100 'best possible health state' (upper anchor). Patients indicated their health state by marking the VAS, while considering the anchors [18]. The HADS is a self-report instrument that exists of two 7-item scales: one for anxiety and one for depression each with a score range of 0-21; a lower score indicating less anxiety or depression $[14,19]$. Finally, the SCL-90 is a 90-item inventory that is used to measure the psychological symptom status. The SCL-90 exists of one overall score and eight symptom subscales: anxiety, agoraphobia, depression, somatic complaints, insufficiency of acting and thinking, interpersonal sensitivity, hostility, and sleeping problems. Higher scores indicate worse health [16, 20]. Because the SCL-90 is a long and demanding measure, we decided to apply the SCL-90 only in the $6 \mathrm{M}$ questionnaire.

\section{Analysis}

If induction of labor would be more burdensome, we would expect a differential impact of intervention strategy on the HR-QoL measures, where induction of labor results in a lower HR-QoL. Prior to analysis, we checked for the presence of selective response regarding neonatal outcome, maternal outcome, and mode of delivery; i.e., overrepresentation of either very healthy or very unhealthy patients in our sample. We defined 'adverse neonatal outcome' as the presence of any of the following: fetal death, 5-minute Apgar score $<7$, umbilical artery $\mathrm{pH}<7.05$, admission to neonatal intensive care unit, and/or neonatal death [8, 9]. We defined 'adverse maternal outcome' as admission to the medium care or intensive care unit [8,9].

Regarding short-term differences between the randomized induction of labor and expectant management groups, we analyzed the retrospectively self-reported 4-point scale pain intensity after delivery using Mann-Whitney's $U$ test.

Then, we compared the impact of treatment strategy (following intention to treat) on HR-QoL for the randomized and non-randomized groups separately on the summary measures of the SF-36 (separate report on subscales PCS and MCS), EuroQoL (mobility, self-care, activity, pain/discomfort, anxiety/depression), VAS General Health, and the HADS (anxiety, depression). HR-QoL improvement was defined as the difference score between the baseline and a postpartum measurement. The difference scores were statistically compared between treatment strategies using Student's $t$ test for each measurement separately.

The HR-QoL impact on the SCL-90 summary scores (anxiety, agoraphobia, depression, somatic complaints, insufficiency of acting and thinking, interpersonal sensitivity, hostility, and sleeping problems) at 6 moths postpartum was addressed with Student's unadjusted $t$ test between the randomized intervention strategies.

To explain the changes over time on the 'physical' SF36 PCS and the 'mental' SF-36 MCS scales, we applied a repeated measures linear mixed model with the following explanatory components: time of assessment (baseline; 6 weeks postpartum; 6 months postpartum), intervention strategy following intention to treat (expectant; induction), randomization (no; yes), age ( $\leq 27 ; 28-33$; $\geq 34$ ), ethnicity (indigenous/non-indigenous), pre-pregnancy BMI (underweight; normal weight; overweight), parity (nulliparous, multiparous), educational level (lower; higher), and the interaction terms time of assessment*randomization, and time of assessment*intervention strategy.

Analyses were conducted using SPSS 15.0 for Windows (SPSS Inc, Chicago, IL). A $P$ value of $<.05$ (two sided) was considered to indicate statistical significance. We used post hoc Bonferroni adjustment to adjust for multiple testing.

\section{Results}

\section{Baseline characteristics}

Of the 1102 participants to the DIGITAT study, 650 (56\%) were randomized, whereas $453(44 \%)$ women participated in the non-randomized part of the study. Not all patients were asked for participation because of logistic reasons because study material was not in stock in every hospital; however, this did not lead to systematical exclusion of any patient group to the HR-QoL study. Of the randomized patients, $392(60 \%)$ were asked to participate in the HRQoL study, versus $264(58 \%)$ of the non-randomized patients. Overall, $574(85 \%)$ of the patients who were included in the HR-QoL study responded to at least one questionnaire (Fig. 1). Response rates were 95, 83, 72, and $59 \%$ for questionnaires B1, B2, 6W, and 6M, respectively.

Baseline characteristics of the randomized and nonrandomized HR-QoL participants and of the responding 
and non-responding patients (i.e., patients who did not respond to any questionnaire) are shown in Table 1.

We tested for selective response regarding maternal outcome, neonatal outcome, and mode of delivery. At 6 weeks postpartum, there were no significant differences between responding and non-responding patients in the proportion of composite bad neonatal outcome (14.9\% vs. $10.2 \% ; P=.052)$, the proportion of composite bad maternal outcome $(3.7 \%$ vs. $1.7 \% ; P=.156)$, cesarean section rates $(13.1 \%$ vs. $15.1 \% ; P=.280)$, and the proportion of assisted vaginal delivery (11.4\% vs. $8.1 \%$; $P=.109$ ). At 6 months postpartum, there were also no differences between responding and non-responding patients in the proportion of bad composite neonatal outcome $(14.4 \%$ vs. $10.4 \% ; P=.083)$, the proportion of bad composite maternal outcome (3.9\% vs. $1.4 \% ; P=.090)$, cesarean section rates $(13.1 \%$ vs. $15.3 \% ; P=.251)$, and the proportion of assisted delivery (10.8\% vs. $8.4 \%$; $P=.192)$. These results are not tabulated.

\section{Self-reported pain after delivery}

There were differences on the retrospectively self-reported pain at days $4(P=.006)$ and $7(P=.003)$ after delivery between the randomized groups in favor of induction of labor. Figure 2 shows the pain distributions at days 1, 4, and 7 after delivery per randomized group.
Summary measures

One-way ANOVA analyses between the average difference scores of the two randomized groups at 6 weeks and 6 months postpartum are shown in Table 2. At 6 weeks postpartum, only the average difference scores of the SF-36 PCS between the randomized groups were statistically, but not clinically, different ( 8.99 vs. $6.49 ; P=.049)$. At 6 months postpartum, only the average differences on the EuroQoL Pain and Discomfort domain was statistically, but also not clinically, different between the randomized groups (.007 vs. .031; $P=.021$ ). Mean difference scores between the non-randomized groups did not differ significantly either at 6 weeks or at 6 months postpartum. After Bonferroni adjustment, none of the outcomes were significant.

Figure 3 shows the mean scores of the SF36 PCS and MCS for the randomized groups at baseline, 6 weeks postpartum, and 6 months postpartum. The PCS increased substantially over time between baseline and 6 weeks (PCS scores 41.6 vs. $49.3 ; P=.038)$ and between 6 weeks and 6 months postpartum (49.3 vs. 52.2; $P=.045$ ); the PCS was higher than the Dutch population average at 6 months postpartum. The MCS did not vary significantly over time between baseline and 6 weeks (MCS scores 47.6 vs. 47.8; $P=.559)$ and between 6 weeks and 6 months postpartum (47.8 vs. $48.0 ; P=.615$ ). The average MCS score remained below the Dutch population norms (solid line) [11], and both
Table 1 Baseline characteristics of the randomized (Rand) and nonrandomized (NRand) participants who followed induction of labor or expectant monitoring, and the patients who did not return the HQRL questionnaires (non-response); analyses of the randomized versus non-randomized and responses versus non-responses

\begin{tabular}{|c|c|c|c|c|c|c|c|c|}
\hline & \multicolumn{5}{|c|}{ Response, $N=574$} & \multirow{2}{*}{$\begin{array}{l}\text { Non-response } \\
n=100\end{array}$} & \multirow{2}{*}{$\begin{array}{l}\text { Randomized } \\
\text { versus } \\
\text { nonrandomized } \\
P\end{array}$} & \multirow{2}{*}{$\begin{array}{l}\text { Response versus } \\
\text { non-response } \\
P\end{array}$} \\
\hline & $\begin{array}{l}\text { Induction } \\
\text { Rand } \\
n=180\end{array}$ & $\begin{array}{l}\text { Expectant } \\
\text { Rand } \\
n=181\end{array}$ & $\begin{array}{l}\text { Induction } \\
\text { NRand } \\
n=36\end{array}$ & $\begin{array}{l}\text { Expectant } \\
\text { NRand } \\
n=162\end{array}$ & $\begin{array}{l}\text { Total } \\
\text { response } \\
N=574\end{array}$ & & & \\
\hline Age: mean (SD) & $28.0(5.2)$ & $28.0(5.2)$ & $31.2(4.4)$ & $31.8(4.9)$ & $29.3(5.4)$ & $29.5(5.9)$ & $<.001$ & .680 \\
\hline $\begin{array}{l}\text { Months to conceive: } \\
\text { mean (SD) }\end{array}$ & $9.0(16.7)$ & $9.9(18.0)$ & $9.9(19.1)$ & $7.5(10.0)$ & $8.8(15.3)$ & $\mathrm{n} / \mathrm{a}^{\mathrm{a}}$ & .355 & $\mathrm{n} / \mathrm{a}$ \\
\hline $\begin{array}{l}\text { BMI pre-pregnancy: } \\
\text { mean (SD) }\end{array}$ & $23.3(5.3)$ & $23.4(5.2)$ & $22.3(4.9)$ & $22.3(4.0)$ & $23.0(3.9)$ & $22.8(4.6)$ & .003 & .511 \\
\hline Dutch origin: $\%$ & 89.0 & 86.4 & 90.6 & 84.5 & 87.2 & 59.0 & .071 & $<.001$ \\
\hline Has a job: $\%$ & 74.9 & 75.0 & 80.6 & 87.8 & 79.2 & $\mathrm{n} / \mathrm{a}$ & .001 & $\mathrm{n} / \mathrm{a}$ \\
\hline Lives with partner: $\%$ & 88.6 & 88.8 & 90.6 & 93.4 & 90.4 & $\mathrm{n} / \mathrm{a}$ & .071 & $\mathrm{n} / \mathrm{a}$ \\
\hline Nulliparious: \% & 58.6 & 58.5 & 51.6 & 61.4 & 59.3 & 57.0 & .417 & .369 \\
\hline $\begin{array}{l}\text { High educational } \\
\text { level }^{\text {b. }} \%\end{array}$ & 15.6 & 18.6 & 25.8 & 43.5 & 25.9 & 18.0 & $<.001$ & .230 \\
\hline Smoking $^{\mathrm{c}}$ : \% & 45.4 & 38.0 & 24.4 & 25.1 & 32.0 & 37.1 & $<.001$ & .205 \\
\hline
\end{tabular}

a These values are not available because they were asked by HR-QoL questionnaire

b Higher vocational training or university

c Did not quit smoking before the second trimester 


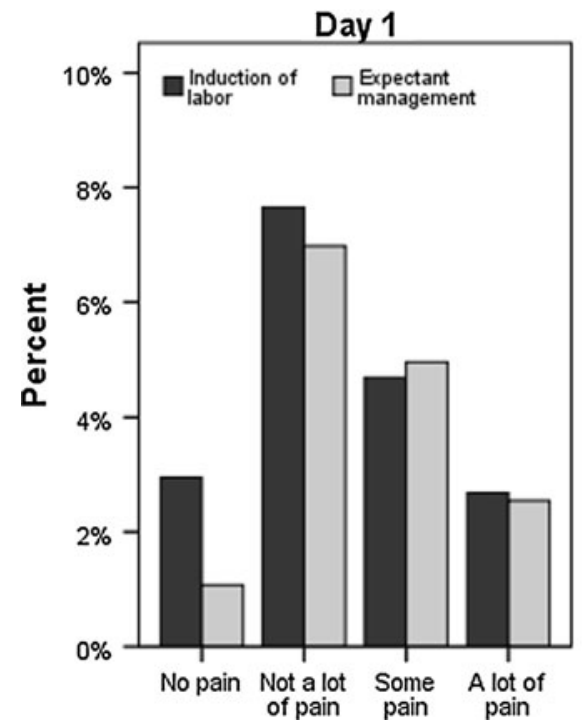

Day after delivery

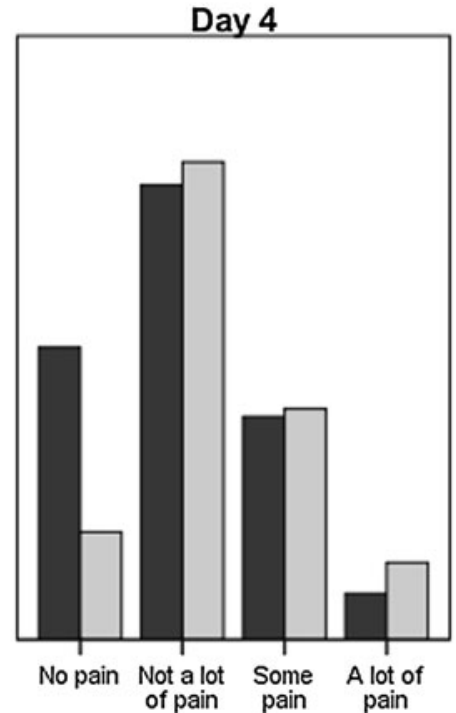

Day 7

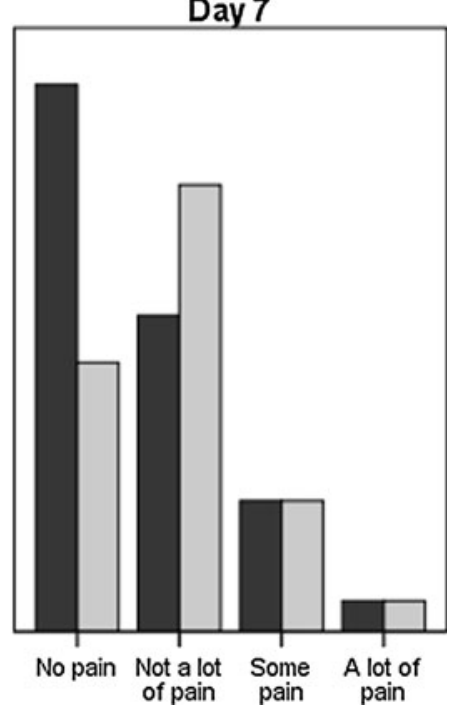

Fig. 2 In retrospect self-reported pain at days 1, 4, and 7 after delivery between the randomized induction of labor and expectant management group

Table 2 Average HR-QoL difference scores $(\Delta)$ per summary measure: comparisons between randomized groups (Rand) and between nonrandomized (Nonrand) groups (Ind = induction of labor; Exp = expectant monitoring) at 6 weeks and 6 months postpartum

\begin{tabular}{|c|c|c|c|c|c|c|c|c|c|c|c|c|}
\hline \multirow[t]{2}{*}{ Summary measure } & \multicolumn{3}{|c|}{$\begin{array}{l}\Delta \text { inclusion, } 6 \text { weeks } \\
\text { postpartum (Rand), } \\
n=241\end{array}$} & \multicolumn{3}{|c|}{$\begin{array}{l}\Delta \text { inclusion, } 6 \text { months } \\
\text { postpartum (Rand), } \\
n=198\end{array}$} & \multicolumn{3}{|c|}{$\begin{array}{l}\Delta \text { inclusion, } 6 \text { weeks } \\
\text { postpartum (Nonrand), } \\
n=139\end{array}$} & \multicolumn{3}{|c|}{$\begin{array}{l}\Delta \text { inclusion, } 6 \text { months } \\
\text { postpartum (Nonrand), } \\
n=118\end{array}$} \\
\hline & Ind & Exp & $P$ & Ind & Exp & $P$ & Ind & Exp & $P$ & Ind & Exp & $P$ \\
\hline SF-36 PCS & 8.99 & 6.49 & .049 & 11.80 & 9.72 & .121 & 4.73 & 6.74 & .295 & 12.06 & 11.62 & .832 \\
\hline SF-36 MCS & -1.32 & -1.14 & .894 & -.67 & -.21 & .784 & -4.11 & -1.22 & .185 & -3.10 & .76 & .086 \\
\hline EuroQoL mobility & .017 & .023 & .367 & .017 & .033 & .102 & .036 & .017 & .191 & .044 & .022 & .196 \\
\hline EuroQoL self-care & .014 & .010 & .336 & .015 & .013 & .536 & .007 & .009 & .772 & .007 & .010 & .751 \\
\hline EuroQoL activity & .048 & .047 & .988 & .049 & .053 & .727 & .031 & .044 & .373 & .048 & .060 & .492 \\
\hline EuroQoL pain/discomfort & .018 & .027 & .356 & .007 & .031 & .021 & .015 & .10 & .660 & .009 & .009 & .969 \\
\hline EuroQoL anxiety/depression & .008 & .004 & .527 & .006 & .005 & .898 & .016 & .011 & .558 & .020 & .007 & .336 \\
\hline VAS general health & 1.02 & 2.09 & 649 & .64 & 4.17 & .149 & 4.75 & 2.98 & .497 & 8.67 & 4.15 & .143 \\
\hline HADS anxiety & -1.58 & -1.74 & .761 & -1.12 & -1.28 & .786 & -.50 & -.51 & .989 & -.61 & -.33 & .740 \\
\hline HADS depression & -1.13 & -1.90 & .105 & -.87 & -1.74 & .131 & -.32 & -.88 & .368 & -.88 & -.84 & .962 \\
\hline
\end{tabular}

the PCS and MCS remained below the US norms for women between 25 and 35 years old (dotted line) [21].

At 6 months postpartum, there were no HR-QoL differences between the induction of labor and the expectant management (randomized) groups on the SCL-90 summary score $(P=.711)$, or on its sub-scores anxiety $(P=.756)$, agoraphobia $(P=.884)$, depression $(P=.909)$, somatic complaints $(P=.483)$, insufficiency of acting and thinking $(P=.608)$, interpersonal sensitivity $(P=.888)$, hostility $(P=.792)$, and sleeping problems $(P=.914)$. These results are not tabulated.
Multivariate mixed model

Table 3 shows the results of the multivariate mixed model explaining the change of PCS and MCS over time, taking some background characteristics and intervention features into account. The $\beta$-coefficients represent the change in the dependent variable when the covariate changes with one unit of measurement. PCS improved substantially after childbirth (6 weeks postpartum: $\beta=5.84, \quad P<.001$; 6 months postpartum: $\beta=10.65, P<.001)$. The MCS did not vary over time (6 weeks postpartum: $\beta=-.77$, 
Fig. 3 Error bars with 95\% confidence interval (CI) of the randomized groups for induction of labor or expectant monitoring on the PCS and MCS at inclusion, at 6 weeks postpartum, and at 6 months postpartum. The horizontal lines indicate mean Dutch population norm scores (solid line) and US population norm scores for women aged $25-34$

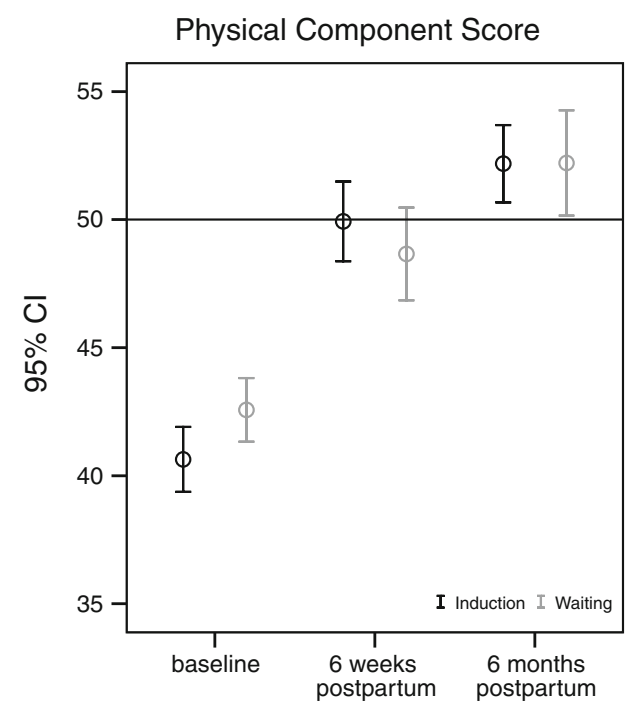

$P=.557 ; 6$ months postpartum: $\beta=1.73, P=.241$ ) There was no effect of randomization (i.e., participating to the trial as a randomized patient or a non-randomized patient) on PCS ( $\beta=-.62, P=.493)$ or MCS ( $\beta=1.09$, $P=.376)$. Intervention according intention to treat was not significant on either PCS (induction of labor: $\beta=$ $-1.47, P=.090)$ or $\operatorname{MCS}(\beta=.92, P=.376)$. Of the background characteristics, high BMI had significant effect on PCS $(\beta=-1.47, P=.015)$ and age had significant effect on MCS $(\leq 27$ years vs. $28-33$ years: $\beta=2.71$, $P=.001)$. None of the interaction effects were significant on either PCS or MCS. After post hoc Bonferroni adjustment, BMI did not have significant effect.

\section{Discussion}

We investigated the effect of induction of labor compared to expectant monitoring on health-related quality of life (HRQoL) of women with an intrauterine growth retardation (IUGR) pregnancy beyond 36 weeks of gestation. We found a difference in self-reported pain at day 4 and day 7 after delivery in favor of induction of labor. However, this difference did not result in HR-QoL differences at 6 weeks or 6 months postpartum between the treatments. We did not find any clinically relevant HR-QoL differences between the randomized and non-randomized groups. The physical and mental health as measured with SF-36 were below the Dutch population average at inclusion. The physical health improved over time and was above Dutch population norms at 6 months postpartum but not above adjusted norm scores for gender and age from the US population. Mental health stayed under the Dutch and US norms.

Maternal HR-QoL has been defined as a secondary outcome to the DIGITAT (Disproportionate Intrauterine Growth Intervention Trial At Term) trial [8, 9]. The clinical outcomes of the DIGITAT trial have already shown that induction of labor and expectant monitoring result in equal neonatal and maternal outcomes. Cesarean section rates were also comparable in pregnancies with IUGR beyond 36 weeks of gestation. Other results of the clinical study showed that labor was eventually induced in $49 \%$ of the patients in the expectant management arm of the trial, and in the induction arm $5 \%$ of the patients had a spontaneous start of the delivery. We have analyzed our HR-QoL data following intention to treat so that our results have captured the effect of initial treatment choice.

Our study has some limitations. First, the patients filled out the questionnaires just once during pregnancy at baseline, regardless of the period between inclusion to the study and childbirth. Therefore, we do not know the shortterm impact of waiting, antenatal stress, and/or anxiety on HR-QoL during the expectant management period. However, the long-term effect of waiting on HR-QoL was probably small since the average difference of the waiting period was not more than 10 days. Second, we have asked women to report their pain retrospectively, which may not have reflected their real perceived pain but rather their wellbeing during their postpartum period. Further study is needed to gain insight to prospectively self-report of pain after the two treatment strategies. We also do not know how the self-perceived intensity and duration of pain developed between the 7th day and the 6th week after delivery, as we do not have measures between those two time points. Third, we have observed a lower response of non-Dutch women, which may reflect the proportion of women who have difficulties with understanding and/or reading the Dutch or English languages. We have seen that non-indigenous women have somewhat lower HR-QoL scores, which indicates that the total group may have had a lower HR-QoL score. Fourth, prior exclusion of women with illnesses and adverse conditions to the DIGITAT trial 
Table 3 Multivariate mixed model with repeated measures: estimates of main and interaction effects and covariates with $95 \%$ confidence interval (CI) on the SF-36 Physical Component Score (PCS) and the Mental Component Score (MCS), N = 314

\begin{tabular}{|c|c|c|c|c|c|c|}
\hline \multirow[t]{2}{*}{ Parameter } & \multicolumn{3}{|l|}{ PCS } & \multicolumn{3}{|l|}{ MCS } \\
\hline & Estimate $(\beta)$ & $P$ & $95 \% \mathrm{CI}$ & Estimate $(\beta)$ & $P$ & $95 \% \mathrm{CI}$ \\
\hline Intercept & 43.38 & $<.001$ & 40.89 to 45.86 & 44.53 & $<.001$ & 41.55 to 47.52 \\
\hline \multicolumn{7}{|l|}{ Time } \\
\hline Baseline & Ref & & & Ref & & \\
\hline 6 weeks postpartum (6Wpp) & 5.84 & $<.001$ & 3.56 to 8.11 & -.77 & .557 & -3.35 to 1.80 \\
\hline 6 months postpartum $(6 \mathrm{Mpp})$ & 10.65 & $<.001$ & 8.38 to 12.93 & 1.73 & .241 & -1.17 to 4.62 \\
\hline \multicolumn{7}{|l|}{ Randomization status } \\
\hline Not randomized & Ref & & & Ref & & \\
\hline Randomized & -.62 & .493 & -2.41 to 1.16 & 1.09 & .320 & -1.07 to 3.26 \\
\hline \multicolumn{7}{|l|}{ Intervention following ITT ${ }^{\mathrm{a}}$} \\
\hline Expectant monitoring & Ref & & & Ref & & \\
\hline Induction of labor & -1.47 & .90 & -3.16 to .23 & .92 & .376 & -1.13 to 2.97 \\
\hline \multicolumn{7}{|l|}{ Age } \\
\hline$\leq 27$ years & Ref & & & Ref & & \\
\hline $28-33$ years & .98 & .141 & -.33 to 2.29 & 2.71 & .001 & 1.15 to 4.28 \\
\hline$\geq 34$ years & .95 & .228 & -.60 to 2.50 & 1.54 & .104 & -.32 to 3.39 \\
\hline \multicolumn{7}{|l|}{ Parity } \\
\hline Nulliparous & Ref & & & Ref & & \\
\hline Multiparous & .14 & .814 & -1.01 to 1.28 & -1.16 & .096 & -2.53 to .21 \\
\hline \multicolumn{7}{|l|}{ Indigenous (Dutch) origin } \\
\hline Yes & Ref & & & Ref & & \\
\hline No & -.41 & 642 & -2.16 to 1.33 & -1.96 & .066 & -4.04 to .13 \\
\hline \multicolumn{7}{|l|}{ BMI pre-pregnancy } \\
\hline$<18.5$ (underweight) & -.73 & .542 & -2.96 to 1.50 & -.29 & .830 & -2.94 to 2.36 \\
\hline $18.5-25$ (normal weight) & Ref & & & Ref & & \\
\hline$>25$ (overweight) & -1.47 & .015 & -2.65 to -.28 & -.34 & .641 & -1.76 to 1.08 \\
\hline \multicolumn{7}{|l|}{ Educational level } \\
\hline Lower & Ref & & & Ref & & \\
\hline Higher & .75 & .270 & -.58 to 2.07 & -1.12 & .167 & -.47 to 2.70 \\
\hline \multicolumn{7}{|l|}{ Interactions } \\
\hline $6 \mathrm{Wpp} *$ randomized & .53 & .719 & -2.37 to 3.44 & 1.63 & .330 & -1.66 to 4.93 \\
\hline $6 \mathrm{Mpp} *$ randomized & -1.32 & .372 & -4.21 to 1.58 & -.08 & .965 & -3.77 to 3.61 \\
\hline $6 \mathrm{Wpp} *$ induction of labor ITT & 1.75 & .226 & -1.08 to 4.59 & -.20 & .904 & -3.41 to 3.01 \\
\hline $6 \mathrm{Mpp} *$ induction of labor ITT & 1.62 & .257 & -1.19 to 4.44 & -.68 & .709 & -4.26 to 2.90 \\
\hline
\end{tabular}

${ }^{\text {a } I T T ~ i n t e n t i o n ~ t o ~ t r e a t ~}$

may have its obvious impact on mean HR-QoL scores. Our mean HR-QoL scores are therefore not applicable to the total group of women with IUGR. Finally, outcomes of the trial suggest that prior treatment preferences exist: most $(80 \%)$ of the non-randomized women were monitored expectantly. However, the differences in the randomized and non-randomized groups, which differed in terms of socio-economic status, did not influence responsiveness or the SF-36 PCS or MCS scores.

An issue that needs further investigation is the fact that average PCS and MCS scores were lower than the population reference norms. The mental health of the DIGITAT patients has been low at all three measurement points. We did not find any systematic effect of educational level, as a proxy of socio-economic status, on the MCS scores. Previous HR-QoL study in women after gestational hypertension or preeclampsia at term randomized for induction of labor or expectant management showed equal to population average MCS scores at 6 weeks and 6 months postpartum [22]. This suggests that the findings of the DIGITAT trial are not due to general lower mental health after childbirth. Our findings may, however, have a relation to the mother's concerns, uncertainty or anxiety about the child's health, which is in general suboptimal in the 
DIGITAT trial as compared to the health of the children from the previous HR-QoL study.

We have presented the results based on the outcomes of the randomized groups. It would also be interesting to look at differences in HR-QoL by trial outcomes-e.g., those with cesarean section versus those without, those with an adverse maternal or neonatal outcome versus those without. As we have insufficient statistical power to make such an analysis within DIGITAT data alone, we are planning such an analysis together with HR-QoL data from the HYPITAT study, a similar trial on induction of labor versus expectant management in case of hypertensive disease at term [22].

In summary, in women with IUGR at term, maternal HRQoL is comparable after induction of labor or expectant monitoring at the long term. Women report to have had less pain after induction of labor as compared to expectant management in the first week after delivery. In women with a IUGR pregnancy beyond 36 weeks of gestation, induction of labor does not affect maternal quality of life on the long term.

Acknowledgments We thank all participants to the study. We thank all members of the Dutch obstetric consortium (http://www.studiesobsgyn.nl/), especially the research nurses, Zelda van Dijk, and Maya Kruijt for their administrative support. We thank ZonMw, The Hague, The Netherlands, for the financial support (grant number 945-04-558).

Open Access This article is distributed under the terms of the Creative Commons Attribution Noncommercial License which permits any noncommercial use, distribution, and reproduction in any medium, provided the original author(s) and source are credited.

\section{Appendix}

In addition to the authors, the following Dutch institutions and gynecologists participated in the DIGITAT trial: Twenteborg Hospital, Almelo-P. J. A. van der Lans MD; Flevo Hospital, Almere-G. Kleiverda MD PhD; Meander Medical Center, Amersfoort-P. C. M. van der Salm MD; Onze Lieve Vrouwe Gasthuis, Amsterdam-D. J. Bekedam MD PhD; Saint Lucas Andreas Hospital, Amsterdam-M. H. Heres MD PhD; Gelre Hospital, Apeldoorn-A. J. M. Huisjes MD; Hospital Rijnstate, Arnhem-K. de Boer MD PhD; Amphia Hospital, Breda-D. N. M. Papatsonis MD PhD; Scheper Hospital, Emmen-M. Burggraaff MD PhD; Bronovo Hospital, Den Haag-W. J. van Wijngaarden MD PhD; Albert Schweizer Hospital, Dordrecht-B. M. C. Akerboom MD; Catharina Hospital, Eindhoven-T. H. M. Hasaart MD PhD; Groene Hart Ziekenhuis, Gouda-C. A. van Meir MD PhD; Martini Hospital, Groningen-A. J. van Loon MD PhD; University Medical Center, Groningen-M. G. van Pampus MD PhD; Spaarne Hospital, Hoofddorp-A. Lub MD; Bethesda, Hoogeveen-M. J. C. P. Hanssen MD;
Medical Center Leeuwarden-D. Perquin MD PhD; Diaconessenhuis, Leiden-F. J. A. Copraij MD; Leiden University Medical Center, Leiden-K. W. M. Bloemenkamp MD PhD; Maastricht University Medical Center, Maastricht-C. Willekes MD PhD; Saint Antonius Hospital, Nieuwegein-E. van Beek MD PhD; Canisius-Wilhelmina Hospital, Nijmegen_-J. M. J. Sporken MD PhD; Maasland Hospital, Sittard-R. Aardenburg MD PhD; Twee Steden Hospital, Tilburg-A. P. Drogtrop MD; Sint Elisabeth Hospital, Tilburg-A. Franx MD PhD; University Medical Center, Utrecht-A. Kwee MD PhD; Vie Curie Hospital, Venlo-E. J. Wijnen MD; Zaans Medical Center, Zaandam-J. P. R. Doornbos MD PhD.

\section{References}

1. Balcazar, H., Keefer, L., \& Chard, T. (1994). Use of anthropometric indicators and maternal risk factors to evaluate intrauterine growth retardation in infants weighing more than 2500 grams at birth. Early Human Development, 36(3), 147-155.

2. Chang, T. C., Robson, S. C., Spencer, J. A., \& Gallivan, S. (1994). Prediction of perinatal morbidity at term in small fetuses: Comparison of fetal growth and Doppler ultrasound. British Journal of Obstetrics and Gynaecology, 101(5), 422-427.

3. Ohel, G., \& Ruach, M. (1996). Perinatal outcome of idiopathic small for gestational age pregnancies at term: The effect of antenatal diagnosis. International Journal of Gynecology \& Obstetrics, 55(1), 29-32.

4. Dijxhoorn, M. J., Visser, G. H., Touwen, B. C., \& Huisjes, H. J. (1987). Apgar score, meconium and acidaemia at birth in smallfor-gestational age infants born at term, and their relation to neonatal neurological morbidity. British Journal of Obstetrics and Gynaecology, 94(9), 873-879.

5. Doctor, B. A., O'Riordan, M. A., Kirchner, H. L., Shah, D., \& Hack, M. (2001). Perinatal correlates and neonatal outcomes of small for gestational age infants born at term gestation. American Journal of Obstetrics and Gynecology, 185(3), 652-659.

6. Villar, J., De, O. M., Kestler, E., Bolanos, F., Cerezo, R., \& Bernedes, H. (1990). The differential neonatal morbidity of the intrauterine growth retardation syndrome. American Journal of Obstetrics and Gynecology, 163(1 Pt 1), 151-157.

7. van den Hove M. M., Willekes C., Roumen F. J., \& Scherjon S. A. (2006). Intrauterine growth restriction at term: Induction or spontaneous labour? Disproportionate intrauterine growth intervention trial at term (DIGITAT): A pilot study. European Journal of Obstetrics Gynecology and Reproduction biology, 125(1), 54-58.

8. Boers, K. E., Bijlenga, D., Mol, B. W., LeCessie, S., Birnie, E., van Pampus, M. G., et al. (2007). Disproportionate intrauterine growth intervention trial at term: DIGITAT. BMC Pregnancy Childbirth, 7, 12.

9. Boers, K. E., Vijgen, S. M., Bijlenga, D., van der Post, J. A., Bekedam, D. J., Kwee, A., et al. (2010). Induction versus expectant monitoring for intrauterine growth restriction at term: randomised equivalence trial (DIGITAT). BMJ, 341, c7087.

10. Ware, J. E., Jr., \& Sherbourne, C. D. (1992). The MOS 36-item short-form health survey (SF-36). I. Conceptual framework and item selection. Medical Care, 30(6), 473-483.

11. Aaronson, N. K., Muller, M., Cohen, P. D., Essink-Bot, M. L., Fekkes, M., Sanderman, R., et al. (1998). Translation, validation, 
and norming of the Dutch language version of the SF-36 Health Survey in community and chronic disease populations. Journal of Clinical Epidemiology, 51(11), 1055-1068.

12. Hoeymans, N., van Lindert, H., \& Westert, G. P. (2005). The health status of the Dutch population as assessed by the EQ-6D. Quality of Life Research, 14(3), 655-663.

13. Johnson, J. A., Luo, N., Shaw, J. W., Kind, P., \& Coons, S. J. (2005). Valuations of EQ-5D health states: Are the United States and United Kingdom different? Medical Care, 43(3), 221-228.

14. Zigmond, A. S., \& Snaith, R. P. (1983). The hospital anxiety and depression scale. Acta Psychiatrica Scandinavica, 67(6), 361-370.

15. Bjelland, I., Dahl, A. A., Haug, T. T., \& Neckelmann, D. (2002). The validity of the hospital anxiety and depression scale. An updated literature review. Journal of Psychosomatic Research, 52(2), 69-77.

16. Arrindell, W. A., \& Ettema, J. H. M. (2003). Symptom Checklist. Handleiding bij een multidimensionele psychopathologie-indicator. Lisse, The Netherlands: Swets Test Publishers.

17. Kind, P. (1996). Quality of life and pharmacoeconomics in clinical trials (2nd ed.). Philadelphia, PA: Lippincott-Raven Publishers.
18. Gudex, C., Dolan, P., Kind, P., \& Williams, A. (1996). Health state valuations from the general public using the visual analogue scale. Quality of Life Research, 5(6), 521-531.

19. Spinhoven, P., Ormel, J., Sloekers, P. P., Kempen, G. I., Speckens, A. E., \& Van Hemert, A. M. (1997). A validation study of the hospital anxiety and depression scale (HADS) in different groups of Dutch subjects. Psychological Medicine, 27(2), 363-370.

20. Derogatis, L. R., Lipman, R. S., \& Covi, L. (1973). SCL-90: An outpatient psychiatric rating scale-preliminary report. Psychopharmacology Bulletin, 9(1), 13-28.

21. Ware, J. E., Kosinski, M., Bjorner, J. B., Turner-Bowker, D. M., Gandek, B., \& Maruish, M. E. (2007). User's manual for the SF36v2TM health survey. Second Edition. Lincoln, RI: QualityMetric Incorporated.

22. Bijlenga, D., Koopmans, C. M., Birnie, E., Mol, B. W., van der Post, J. A., Bloemenkamp, K. W., Scheepers, H. C. J., Willekes, C., Kwee, A., Heres, M. H. B., van Beek, E., van Meir, C. A., van Huizen, M. E., van Pampus, M. G., \& Bonsel, G. J. (2011). Quality of life after induction of labor versus expectant monitoring in gestational hypertension or preeclampsia at term. Hypertension Pregnancy (in press). 